University of North Florida

UNIVERSITY of

NORTH FLORIDA.

UNF Digital Commons

Clinical \& Applied Movement Science Faculty

Publications

Department of Clinical \& Applied Movement

Science

2011

\title{
Reliability of the Landing Error Scoring System-Real Time, a Clinical Assessment Tool of Jump-Landing Biomechanics
}

\author{
Darin A. Padua \\ Michelle C. Boling \\ University of North Florida, m.boling@unf.edu \\ Lindsay J. DiStefano \\ James A. Onate \\ Anthony I. Beutler
}

See next page for additional authors

Follow this and additional works at: https://digitalcommons.unf.edu/hmov_facpub

Part of the Rehabilitation and Therapy Commons

\section{Recommended Citation \\ Padua, Darin A.; Boling, Michelle C.; DiStefano, Lindsay J.; Onate, James A.; Beutler, Anthony I.; and Marshall, Stephen W., "Reliability of the Landing Error Scoring System-Real Time, a Clinical Assessment Tool of Jump-Landing Biomechanics" (2011). Clinical \& Applied Movement Science Faculty Publications. 2. \\ https://digitalcommons.unf.edu/hmov_facpub/2}

This Article is brought to you for free and open access by the Department of Clinical \& Applied Movement Science at UNF Digital Commons. It has been accepted for inclusion in Clinical \& Applied Movement Science Faculty Publications by an authorized administrator of UNF Digital Commons. For more information, please contact Digital Projects.

(C) 2011 All Rights Reserved

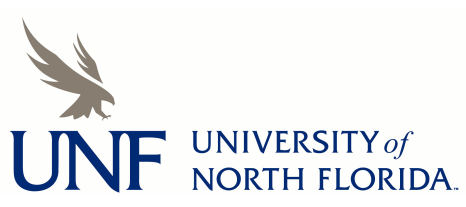




\section{Authors}

Darin A. Padua, Michelle C. Boling, Lindsay J. DiStefano, James A. Onate, Anthony I. Beutler, and Stephen W. Marshall 


\title{
Reliability of the Landing Error Scoring System-Real Time, a Clinical Assessment Tool of Jump-Landing Biomechanics
}

\author{
Darin A. Padua, Michelle C. Boling, Lindsay J. DiStefano, \\ James A. Onate, Anthony I. Beutler, and Stephen W. Marshall
}

Context: There is a need for reliable clinical assessment tools that can be used to identify individuals who may be at risk for injury. The Landing Error Scoring System (LESS) is a reliable and valid clinical assessment tool that was developed to identify individuals at risk for lower extremity injuries. One limitation of this tool is that it cannot be assessed in real time and requires the use of video cameras. Objective: To determine the interrater reliability of a real-time version of the LESS, the LESS-RT. Design: Reliability study. Setting: Controlled research laboratory. Participants: 43 healthy volunteers ( 24 women, 19 men) between the ages of 18 and 23. Intervention: The LESS-RT evaluates 10 jump-landing characteristics that may predispose an individual to lower extremity injuries. Two sets of raters used the LESS-RT to evaluate participants as they performed 4 trials of a jump-landing task. Main Outcome Measures: Intraclass correlation coefficient $\left(\mathrm{ICC}_{2,1}\right)$ values for the final composite score of the LESS-RT were calculated to assess interrater reliability of the LESS-RT. Results: Interrater reliability $\left(\mathrm{ICC}_{2,1}\right)$ for the LESS-RT ranged from .72 to .81 with standard error of measurements ranging from .69 to 79. Conclusions: The LESS-RT is a quick, easy, and reliable clinical assessment tool that may be used by clinicians to identify individuals who may be at risk for lower extremity injuries.

Keywords: anterior cruciate ligament, movement assessment, injury risk

Clinical assessment tools are popular in sports-medicine settings and are commonly used to evaluate balance, movement dysfunctions, and muscle imbalances. ${ }^{1-4}$ The goal of some clinical assessment tools is to provide a brief and easily implementable method to identify problems in the musculoskeletal system that may lead to athletic injury. ${ }^{5,6}$ Such tools provide an efficient method for clinicians to identify individuals who may be at risk for injury. In addition, sports-medicine clinicians

Padua is with the Dept of Exercise and Sport Science, and Marshall, the Dept of Epidemiology, University of North Carolina, Chapel Hill, NC. Boling is with the Dept of Clinical and Applied Movement Sciences, University of North Florida, Jacksonville, FL. DiStefano is with the Dept of Kinesiology, University of Connecticut, Storrs, CT. Onate is with the School of Allied Medical Professions, The Ohio State University, Columbus, OH. Beutler is with the Department of Family Medicine, Uniformed Services University of the Health Sciences, Bethesda, MD. 
can use the results from clinical assessment tools to develop injury-prevention and -rehabilitation programs.

Because of the time demands placed on clinicians, it is important for valid and reliable clinical assessment tools to be developed that can be evaluated in real time, wherein the individual is evaluated through direct visual observation. However, few of the clinical assessment tools available to sports-medicine clinicians allow for real-time analysis. The Balance Error Scoring System and the Star Excursion Balance Test are examples of real-time tools that evaluate balance ability and have demonstrated good reliability. ${ }^{1,2}$ Although balance is important to evaluate in select clinical settings, ${ }^{5}$ it does not directly provide information about an individual's movement technique during sport-specific tasks. The Functional Movement Screen and the Overhead Squat Test can be evaluated in real time but lack reliability and validity information. Although these real-time assessment tools evaluate movement technique during squatting, stepping, and lunging tasks, ${ }^{3}$ they do not assess it during more dynamic, sport-specific tasks that are associated with injury mechanisms, such as landing from a jump. ${ }^{7}$ Several studies have described methods to assess jump-landing biomechanics, but these assessments are not scored in real time and require instrumentation such as force plates,${ }^{8}$ video cameras, ${ }^{9-12}$ and video-editing software. ${ }^{9-11}$ As such, these previously described jump-landing assessments are not performed in real time. The tuck jump assessment, which evaluates jumping and landing mechanics in real time, was recently introduced by Myer et al. ${ }^{13}$ Although this clinical assessment tool allows for real-time analysis of a jump-landing task, it lacks scientific evidence regarding the reliability, validity, and predictive value of the tool.

The Landing Error Scoring System (LESS) is a clinical assessment tool that has demonstrated concurrent validity against 3-dimensional motion analysis, good interrater and intrarater reliability, ${ }^{4}$ and preliminary predictive evidence for identifying individuals who are at high risk for injury. ${ }^{6}$ In addition, the LESS can successfully evaluate changes in landing technique resulting from an injury-prevention program. ${ }^{14} \mathrm{~A}$ clinician can score the LESS quickly, but it requires 2 video cameras and video analysis. The utility of the LESS might be enhanced if it were modified to allow real-time analysis in a clinical setting. Therefore, the purpose of this study was to determine the reliability of a modified LESS, the Landing Error Scoring System-Real Time, or LESS-RT. The LESS-RT was designed to be scored in real time in a clinical setting and provide information about an individual's movement technique during a jump-landing task.

\section{Methods}

\section{Participants}

In all, 43 healthy participants ( 24 women, 19 men; height $172.11 \pm 6.85 \mathrm{~cm}$, mass $70.33 \pm 10.11 \mathrm{~kg}$ ) volunteered for this investigation. All participants were freshmen at the US Military Academy and free from any injury or illness that restricted their physical activity at the academy.

\section{Testing Procedures}

Two separate sessions were used to evaluate the reliability of the LESS-RT. Three raters evaluated participants' landing mechanics using the LESS-RT. All of the raters were certified athletic trainers with over 5 years of clinical experience and 
had previous training and experience with scoring the original LESS from video replay (each rater has scored over 200 separate subjects). Twenty-four participants (11 women, 13 men) were evaluated by raters 1 and 2 during a morning testing session, and 19 participants ( 13 women, 6 men) were evaluated by raters 1 and 3 during an afternoon session. All participants signed an informed consent approved by the university's institutional review board before entering this study.

\section{Administration of the LESS-RT}

All participants performed 4 trials of a standardized jump-landing task. The task required participants to jump forward from a 30-cm-high box, which was set at a distance of $50 \%$ of their height away from the target landing area; land in the target landing area; and immediately rebound by jumping to maximal vertical height on landing (Figure 1). During task instruction, emphasis was placed on participants starting the jump in a neutral position (ie, feet shoulder width apart and toes pointing forward) and jumping as high as they could after their initial landing from the box. Participants were not provided any feedback or coaching on their landing technique
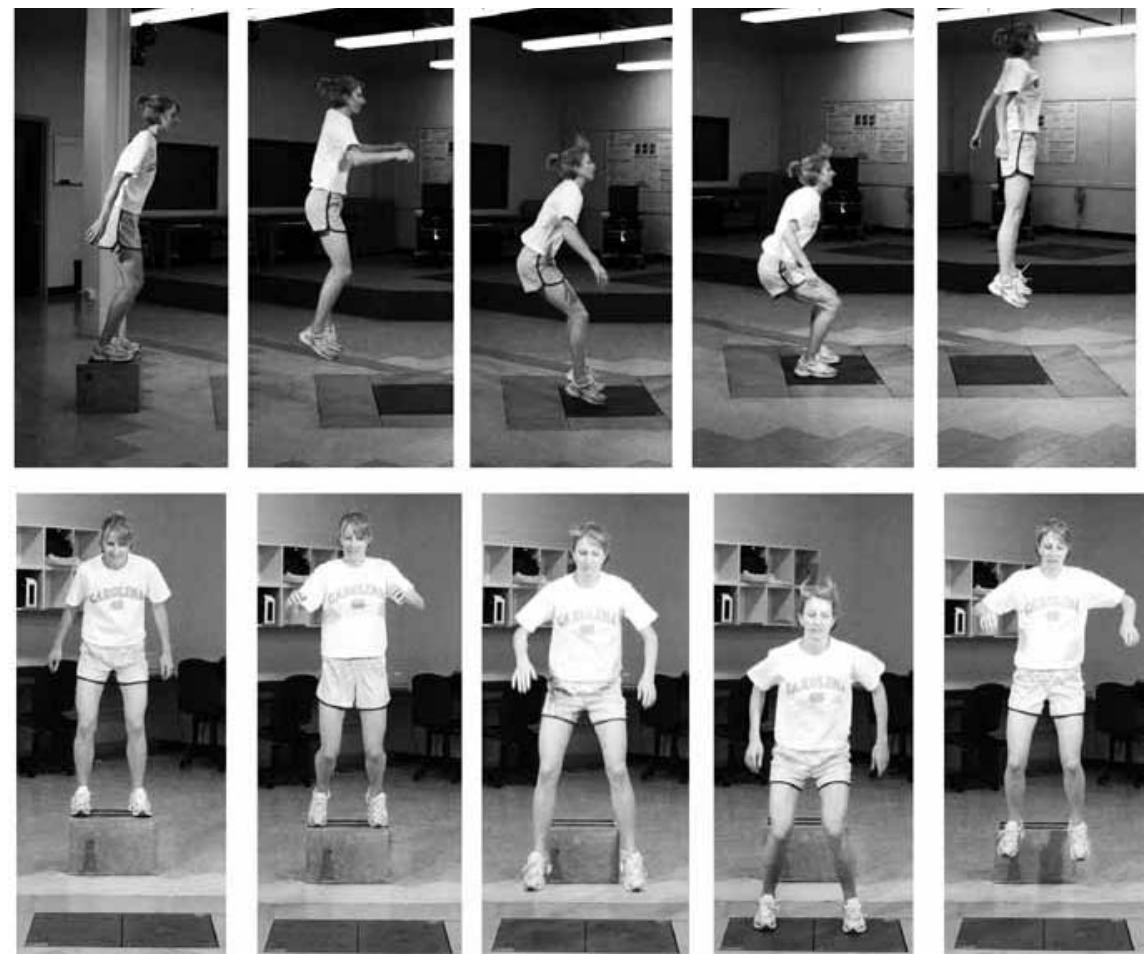

Figure 1 - Standardized jump-landing task performed by subjects during the Landing Error Scoring System-Real Time. Subjects jumped down from the box and landed on the ground and then immediately jumped vertically upward as high as possible. Raters scored jumplanding technique while the subject was in contact with the ground after landing from the box. Subjects were scored from raters' observations in both the sagittal and the frontal plane. 
other than task instructions. They were allowed as many practice trials as needed (typically 2) to perform the task successfully. A successful jump was characterized by both feet simultaneously leaving the box; jumping forward off the box, without a large upward motion after takeoff from the box, to reach the target landing area below; and completing the task in a fluid motion (no pause in movement of body's center of mass after making contact with the ground until takeoff for subsequent jump). If a jump was unsuccessful the subject was simply instructed to repeat the task and did not receive additional instructions.

The LESS-RT was derived from the original LESS. The LESS evaluates 17 jump-landing characteristics and is scored by reviewing a recorded video of a jumplanding task over 3 trials. The LESS-RT includes 10 jump-landing characteristics and is scored over 4 trials of the jump-landing task. An additional trial is required to allow the rater to observe all 10 jump-landing characteristics.

Table 1 provides operational definitions and scoring details for each item. During each trial, raters evaluate specific motions at the feet, knees, and trunk. For trials 1 and 2, raters scored participants from the front. The first trial was used to evaluate stance width, foot rotation, and initial foot contact (ie, whether the feet landed symmetrically; LESS-RT items 1-3). The second trial was used to evaluate knee and trunk frontal-plane motion (LESS-RT items 4 and 5). For trials 3 and 4, raters evaluated the participants from the side. The third trial was used to assess how participants landed from the jump (ie, toe to heel, heel to toe, or flat-footed) and knee sagittal-plane motion (LESS-RT items 6 and 7). The fourth trial was used to evaluate trunk sagittal-plane motion (LESS-RT item 8). LESS-RT items 9 and 10 were scored based on the raters' impression of total motion across all 4 trials of the jump-landing task. Item 9 was scored as an overall impression of sagittalplane joint motion (ie, whether the individual landed "softly"). Item 10 was scored as an overall impression of both frontal- and sagittal-plane motion. The LESS-RT scoring sheet is provided in Figure 2.

Raters viewed both lower extremities when scoring the LESS-RT. If one lower extremity demonstrated an error (ie, foot was externally rotated) and the other lower extremity did not (ie, toes pointed forward), the rater would score the specific item as an error. Each participant received a final composite score, which was calculated by summing all the items on the LESS-RT. Testing and scoring with LESS-RT took approximately 2 minutes per subject.

\section{Statistical Analyses}

Intraclass correlation coefficient (ICC) and standard error of measure (SEM) values were determined to assess interrater reliability $\left(\mathrm{ICC}_{2,1}\right)$ of the LESS-RT's final composite score during the 2 separate testing sessions. All data were analyzed using SPSS (version 15.0, SPSS Inc, Chicago, IL) with an a priori alpha level of .05.

\section{Results}

Means and standard deviations for total LESS-RT scores are presented in Table 2 for each rater. The $\mathrm{ICC}_{2,1}$ and SEM values for interrater reliability between raters 1 and 2 were .81 (95\% confidence interval $=.56-.92)$ and .69 , respectively. Similar values were observed between raters 1 and $3 ; \mathrm{ICC}_{2,1}$ and SEM values were .72 (95\% 


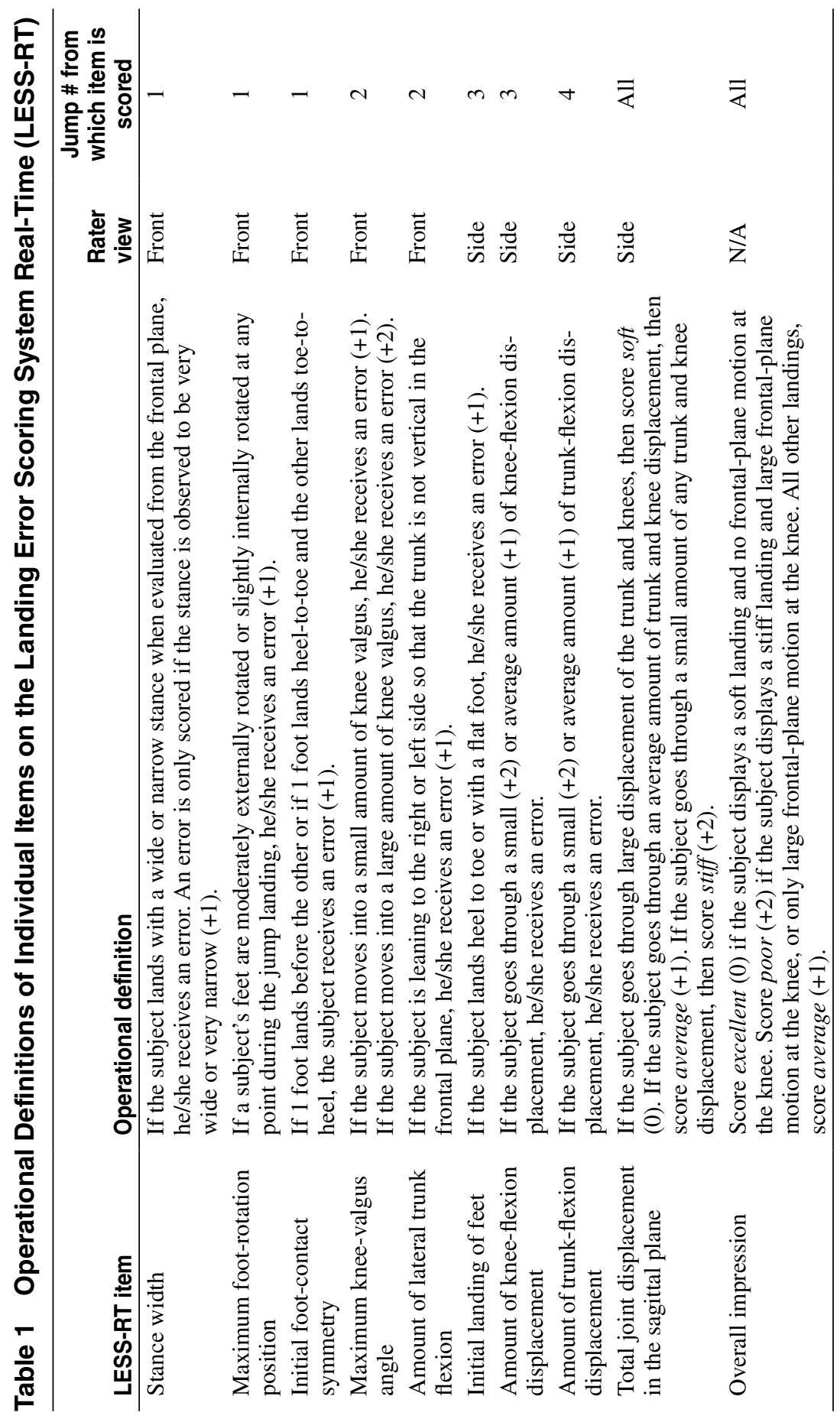




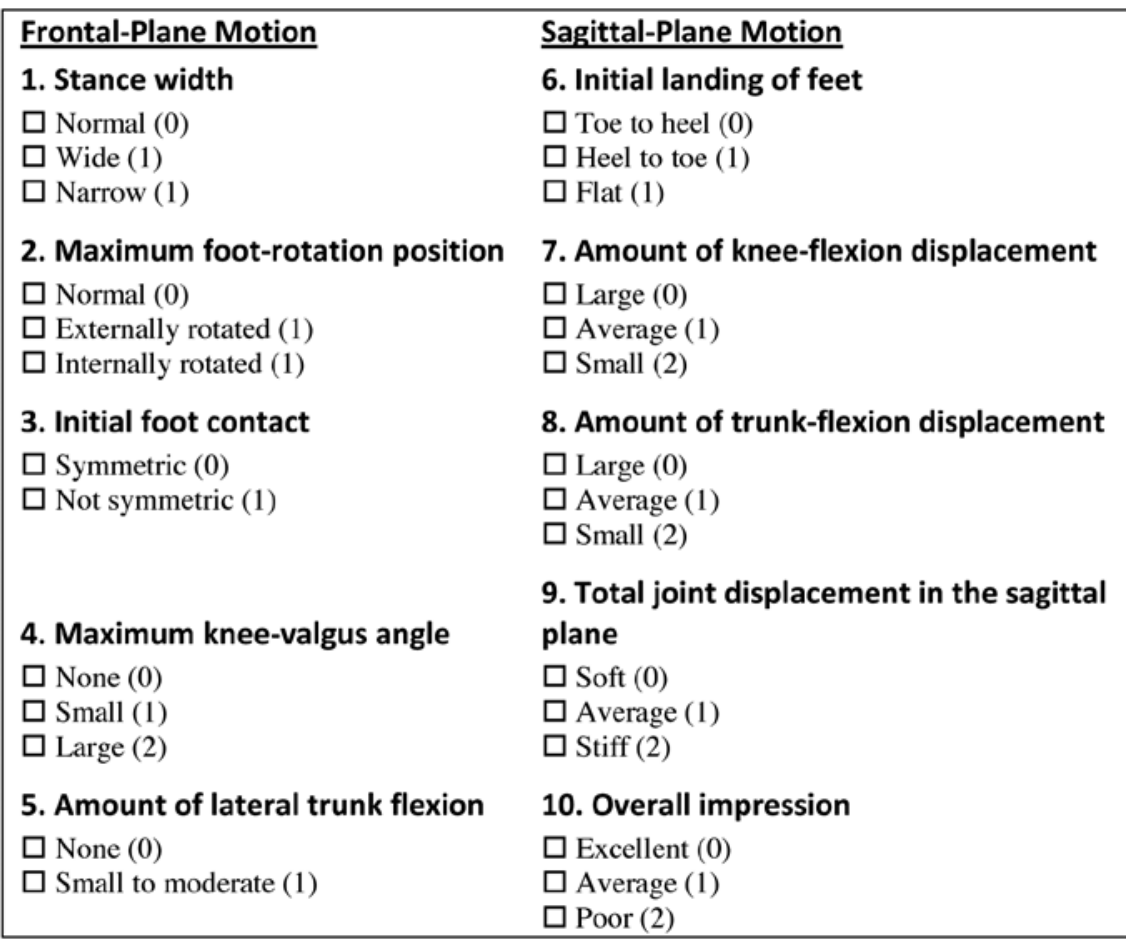

Figure 2 - Scoring sheet for the Landing Error Scoring System-Real Time (LESS-RT) assessment tool.

\begin{tabular}{|c|c|c|c|}
\hline Session & Rater & Mean & SD \\
\hline \multirow[t]{2}{*}{ Morning session } & 1 & 5.8 & 1.6 \\
\hline & 2 & 6.2 & 1.5 \\
\hline \multirow[t]{2}{*}{ Afternoon session } & 1 & 5.3 & 1.3 \\
\hline & 3 & 4.9 & 1.5 \\
\hline
\end{tabular}

confidence interval $=.42-.88$ ) and .79 , respectively. We also assessed the reliability between rater 1 (LESS-RT scores from morning and afternoon sessions) and raters 2 (morning session LESS-RT scores) and 3 (afternoon session LESS-RT scores) combined. The reliability between rater 1 and raters 2 and 3 combined was $\mathrm{ICC}_{2,1}$ $=.79(95 \%$ confidence interval $=.64-.88)$ and $\mathrm{SEM}=.76$. These findings indicate that the LESS-RT has good interrater reliability and precision. 


\section{Discussion}

There is a need to identify individuals at elevated risk for lower extremity injury given the associated high financial costs ${ }^{14}$ and elevated risk of osteoarthritis after injury. ${ }^{15}$ The ability to successfully and rapidly identify individuals at increased risk for lower extremity injury would allow clinicians to target these individuals for injury-prevention training that may reduce their risk for future injury. Select jump-landing biomechanical characteristics have been shown to differ in individuals who go on to sustain an anterior cruciate ligament (ACL) injury, compared with those who do not become injured. ${ }^{16}$ However, these traditional, biomechanical testing procedures require the use of motion-analysis equipment that are not readily accessible in a clinical setting. The LESS has been shown to be a valid clinical assessment of jump-landing biomechanical characteristics. ${ }^{4} \mathrm{~A}$ limitation of the LESS is that testing is performed by recording an individual performing a jump-landing task using standard video cameras and then later scored from review of video recordings. Modified scoring and testing criteria were developed to score individuals' jump-landing movement patterns in real time (LESS-RT) while they performed 4 separate jump-landing trials to further improve the clinical utility of the LESS. Based on the findings of this investigation, the LESS-RT can be performed and scored in real time with good interrater reliability.

Padua et $\mathrm{al}^{4}$ examined the interrater reliability of the original LESS (when scored from video replay) and found good reliability $(\mathrm{ICC}=.84)$ and precision (SEM = .71). The LESS-RT appears to have comparable interrater reliability (ICC range .72-.81) and precision (SEM range .69-.79). In addition, the average overall LESS score obtained using the LESS-RT $(5.6 \pm 1.4)$ is similar to that of the original LESS in the cadet population $(4.9 \pm 1.6) .^{4}$

Padua et $\mathrm{al}^{4}$ also examined the validity of the original LESS by comparing lower extremity biomechanics between individuals with high LESS scores (poor jump-landing technique) and low LESS scores (excellent jump-landing technique). However, we did not compare lower extremity biomechanics in this study. Future research is needed to investigate whether the LESS-RT demonstrates validity similar to that of the original LESS.

Each of the items assessed on the LESS-RT was selected based on the underlying assumption that specific movement patterns may increase one's risk for noncontact ACL injury. Thus, potentially injurious movement patterns in the sagittal, frontal, and transverse planes are identified using the LESS-RT. Sagittalplane movement patterns on the LESS-RT are assessed in items 6 through 9 (Table 1). These movement patterns are believed to be important; video analyses have repeatedly shown the body to be in an erect posture (eg, decreased knee, hip, and trunk flexion) during noncontact ACL-injury events. ${ }^{7,17-19}$ Retrospective studies that interviewed individuals who sustained an ACL injury also indicate that the knee was at or near full extension during the injury event. ${ }^{17}$ Decreased knee flexion is also believed to be an important factor, given how it influences ACL loading (LESS-RT item 7). Decreased knee-flexion angle leads to a greater anterior tibial shear force by increasing the patellar tendon-tibial shaft angle. ${ }^{20}$ As the patellar tendon-tibial shaft angle increases, the quadriceps-induced anterior tibial shear force is also increased. ${ }^{21}$ Thus, small knee-flexion angles may allow for greater quadriceps-induced anterior tibial shear force. Decreased knee-flexion angle also 
minimizes the hamstrings' ability to produce posterior tibial shear force and limits the muscle's ability to offset anterior tibial shear forces. ${ }^{21}$ Trunk and hip flexion are also important sagittal-plane movement patterns; small amounts of trunk and hip flexion are associated with increased vertical ground-reaction force ${ }^{22}$ and decreased knee-flexion angle (LESS-RT item 8). ${ }^{23}$ Females, who are at greater risk for ACL injury than males, have also been repeatedly shown to demonstrate less knee, hip, and trunk flexion than their male counterparts. ${ }^{24-26}$ The foot position at initial contact is also believed to be important because landing with a heel-to-toe movement pattern (landing on heel of foot) results in significantly greater vertical ground-reaction force and rate of force development, external knee- and hip-flexion moment, and quadriceps activation than a forefoot landing movement pattern (landing on metatarsal heads; LESS-RT item 6). ${ }^{27}$ Thus, jump-landing movement patterns consisting of decreased sagittal-plane joint flexion (decreased knee, hip, and trunk flexion) and a heel-to-toe landing pattern were thought to be high-risk movement patterns for noncontact ACL injury and were included as movement errors on the LESS-RT.

Frontal-plane movement patterns are assessed on LESS-RT items 1, 4, and 5. Based on video analysis, forceful valgus collapse (LESS-RT item 4) with the knee near full extension is reported during noncontact ACL-injury events. ${ }^{7,17}$ It is not clear whether the knee valgus reported to occur during noncontact ACL-injury events is an isolated frontal-plane motion resulting in medial joint opening (true knee valgus) or the combined motion of hip internal rotation and adduction as the foot is fixed on the ground (apparent knee valgus). Cadaver-based research indicates that isolated kneevalgus moment increases ACL loading ${ }^{28,29}$; however, the magnitude of ACL loading because of isolated knee-valgus moment is small compared with isolated anterior tibial shear force or tibial internal-rotation moments. Although isolated knee-valgus moment does not place a large load on the ACL, knee valgus is believed to be an important ACL-injury mechanism because the amount of ACL loading is greatly magnified when knee-valgus moment is applied in combination with anterior tibial shear force or tibial internal-rotation moments. ${ }^{28,30,31} \mathrm{In}$ addition, the combination of knee valgus and tibial external rotation also facilitates ACL loading by causing impingement of the ACL against the intercondylar notch. ${ }^{32}$ Thus, the combination of knee valgus with both tibial internal rotation and external rotation may be an important cause of ACL injury. ${ }^{33}$ Video analysis of noncontact ACL injuries further suggests knee valgus to be an important factor because dynamic valgus collapse is observed as the most common movement pattern during noncontact ACL-injury events in female handball and basketball athletes. ${ }^{7,19}$ Research has also repeatedly shown females, who are at greatest risk for ACL injury, to display significantly greater knee valgus than males. ${ }^{25,26,34-37}$ Stance width (LESS-RT item 1) and lateral trunk flexion (LESS-RT item 5) also influence knee-valgus loading during functional tasks. ${ }^{38}$ Individuals performing a side-step cutting task with increased lateral trunk flexion (away from direction of cut) and stance width (foot placed farther away from body) experienced greater external knee-valgus moment. ${ }^{38}$ Lateral trunk flexion and stance width influence the body's center of mass relative to the knee joint, hence facilitating external knee-valgus moments. Increased stance width has also been shown to cause greater external knee-flexion and internal-rotation moments during side-step cutting. ${ }^{38}$ Knee-valgus motion (knees move medial past great toe), 
lateral trunk flexion, and increased stance width during jump-landing maneuvers were included as movement errors on the LESS-RT because these may be high-risk movement patterns associated with noncontact ACL injury.

Initial foot-contact symmetry (LESS-RT item 3) was also included on the LESS-RT as a frontal-plane variable because it may influence the load distribution on the lower extremity. Individuals performing jump-landing maneuvers with asymmetric foot contact ( 1 foot contacts ground before the other) will place a greater load on the limb initially contacting the ground as the initial impact is absorbed by only 1 limb. Increased loading may place that limb at greater risk of injury. Video analyses of noncontact ACL injuries during team handball demonstrate that most injuries occurred with 1 foot in contact with the ground. ${ }^{7}$ In addition, an asymmetric foot-contact pattern may cause the individual to land out of control/balance by minimizing the base of support at initial contact. Outof-control landing maneuvers are often described as a common mechanism of noncontact ACL injury. ${ }^{7}$

Foot position (toe-in or toe-out; LESS-RT item 2) serves as a marker for tibial rotation during the jump-landing maneuver. The importance of foot position is demonstrated as Olsen et $\mathrm{al}^{7}$ describe noncontact ACL injuries to occur as the knee undergoes internal or external rotation in combination with knee valgus. Tibial internal rotation creates greater tensile load on the ACL, ${ }^{28}$ and external rotation of the tibia has been shown in MRI-based modeling studies to cause the ACL to impinge on the lateral wall of the femoral intercondylar notch. ${ }^{32,39}$ Therefore, excessive or uncontrolled amounts of toe-in (tibial internal rotation) or toe-out (tibial external rotation) may produce ACL loading. The magnitude of ACL loading induced by tibial internal rotation (toe-in) is magnified when the loading is applied in combination with anterior tibial shear force ${ }^{28}$ or knee-valgus moment. ${ }^{28,31}$ Foot position has also been shown to influence knee loading; toe-out movement patterns increase laterally directed ground-reaction forces during landing ${ }^{40}$ and increase external knee-flexion moments. ${ }^{38}$ As a result, performing jump-landing tasks with either toe-in or toe-out movement patterns was included as a movement error on the LESS-RT.Our current investigation clearly shows that the LESS-RT is reliable and time-efficient and has carefully designed construct validity. However, the study has several important limitations. The LESS-RT has not been correlated with biomechanical data or injury outcomes. These studies are currently ongoing. In addition, raters for the LESS-RT in this investigation had extensive previous experience with traditional LESS scoring and other clinical assessment tools for human movement. Future investigations are needed to determine the reliability of the LESS-RT in individuals with less experience in human-movement analysis. We also acknowledge that the traditional reliability study would have involved all 3 raters scoring all subjects; however, because of the time constraints of the testing schedule, we elected to pursue 2 smaller 2-rater studies rather than 1 larger 1-rater study. We anticipate that this design modification had negligible effect on the study conclusions as evidenced by the overlap in $95 \%$ confidence intervals across ICC values between raters. Finally, participants were incoming male and female freshmen at the US Military Academy at West Point and were not exclusively female high-school- or college-age athletes. This should be considered when interpreting the generalizability of these findings. 


\section{Summary}

The LESS-RT demonstrates good interrater reliability and compares very favorably with the original LESS, which required use of video cameras and replay of videotapes for scoring. We believe that with proper training, clinicians may be able to use the LESS-RT as a clinical screening tool to identify individuals who may be at greater risk for noncontact ACL or other lower extremity injuries. Training materials for the LESS-RT are located at the following Web site: www.unc.edu/ sportmedlab/LESS-RT

\section{References}

1. Riemann BL, Guskiewicz KM, Shields EW. Relationship between clinical and forceplate measures of postural stability. J Sport Rehabil. 1999;8:71-82.

2. Hertel J, Miller S, Denegar CR. Intratester and intertester reliability during the Star Excursion Balance Test. J Sport Rehabil. 2000;9:104-116.

3. Kiesel K, Plisky P, Voight M. Can serious injury in professional football be predicted by a preseason functional movement screen? NAm J Sports Phys Ther. 2007;2(3):147-158.

4. Padua DA, Marshall SW, Boling MC, Thigpen CA, Garrett WE, Jr, Beutler AI. The Landing Error Scoring System (LESS) is a valid and reliable clinical assessment tool of jump-landing biomechanics: The JUMP-ACL study. Am J Sports Med. 2009;37(10):1996-2002.

5. McGuine TA, Greene JJ, Best T, Leverson G. Balance as a predictor of ankle injuries in high school basketball players. Clin J Sport Med. 2000;10(4):239-244.

6. DiStefano LJ, Padua DA, DiStefano MJ, Marshall SW. The Landing Error Scoring System predicts non-contact injury in youth soccer players. Med Sci Sports Exerc. 2009;41(5 Suppl 1):520-521.

7. Olsen OE, Myklebust G, Engebretsen L, Bahr R. Injury mechanisms for anterior cruciate ligament injuries in team handball: a systematic video analysis. Am J Sports Med. 2004;32(4):1002-1012.

8. Hewett TE, Myer GD, Ford KR, Slauterbeck JR. Preparticipation physical examination using a box drop vertical jump test in young athletes: the effects of puberty and sex. Clin J Sport Med. 2006;16(4):298-304.

9. Noyes FR, Barber-Westin SD, Fleckenstein C, Walsh C, West J. The drop-jump screening test: difference in lower limb control by gender and effect of neuromuscular training in female athletes. Am J Sports Med. 2005;33(2):197-207.

10. Barber-Westin SD, Noyes FR, Galloway M. Jump-land characteristics and muscle strength development in young athletes: a gender comparison of 1140 athletes 9 to 17 years of age. Am J Sports Med. 2006;34(3):375-384.

11. Barber-Westin SD, Galloway M, Noyes FR, Corbett G, Walsh C. Assessment of lower limb neuromuscular control in prepubescent athletes. Am J Sports Med. 2005;33(12):1853-1860.

12. Ekegren CL, Miller WC, Celebrini RG, Eng JJ, Macintyre DL. Reliability and validity of observational risk screening in evaluating dynamic knee valgus. J Orthop Sports Phys Ther. 2009;39(9):665-674.

13. Myer GD, Ford KR, Hewett TE. Tuck jump assessment for reducing anterior cruciate ligament injury risk. Athl Ther Today. 2008;13(5):39-44.

14. DiStefano LJ, Padua DA, DiStefano MJ, Marshall SW. Influence of age, sex, technique, and exercise program on movement patterns after an anterior cruciate ligament injury prevention program in youth soccer players. Am J Sports Med. 2009;37(3):495-505. 
15. Lohmander LS, Ostenberg A, Englund M, Roos H. High prevalence of knee osteoarthritis, pain, and functional limitations in female soccer players twelve years after anterior cruciate ligament injury. Arthritis Rheum. 2004;50(10):3145-3152.

16. Hewett TE, Myer GD, Ford KR, et al. Biomechanical measures of neuromuscular control and valgus loading of the knee predict anterior cruciate ligament injury risk in female athletes: a prospective study. Am J Sports Med. 2005;33(4):492-501.

17. Boden BP, Dean GS, Feagin JA, Garrett WE. Mechanisms of anterior cruciate ligament injury. Orthopedics. 2000;23(6):573-578.

18. Ireland ML. Anterior cruciate ligament injury in female athletes: epidemiology. $J$ Athl Train. 1999;34(2):150-154.

19. Krosshaug T, Nakamae A, Boden BP, et al. Mechanisms of anterior cruciate ligament injury in basketball: video analysis of 39 cases. Am J Sports Med. 2007;35(3):359-367.

20. Nunley RM, Wright D, Renner JB, Yu B, Garrett WE Jr. Gender comparison of patellar tendon tibial shaft angle with weight bearing. Res Sports Med. 2003;11:173-185.

21. Li G, Sakane R, Kanamori A, Ma C, Woo S. The importance of quadriceps and hamstring muscle loading on knee kinematics and in-situ forces in the ACL. J Biomech. 1999;32:395-400.

22. Devita P, Skelly WA. Effect of landing stiffness on joint kinetics and energetics in the lower extremity. Med Sci Sports Exerc. 1992;24(1):108-115.

23. Blackburn JT, Padua DA. Influence of trunk flexion on hip and knee joint kinematics during a controlled drop landing. Clin Biomech (Bristol, Avon). 2008;23(3):313-319.

24. Chappell JD, Creighton RA, Giuliani C, Yu B, Garrett WE. Kinematics and electromyography of landing preparation in vertical stop-jump: risks for noncontact anterior cruciate ligament injury. Am J Sports Med. 2007;35(2):235-241.

25. Malinzak RA, Colby SM, Kirkendall DT, Yu B, Garrett WE. A comparison of knee joint motion patterns between men and women in selected athletic tasks. Clin Biomech (Bristol, Avon). 2001;16:438-445.

26. McLean SG, Walker KB, van den Bogert AJ. Effect of gender on lower extremity kinematics during rapid direction changes: an integrated analysis of three sports movements. J Sci Med Sport. 2005;8(4):411-422.

27. Kovacs I, Tihanyi J, Devita P, Racz L, Barrier J, Hortobagyi T. Foot placement modifies kinematics and kinetics during drop jumping. Med Sci Sports Exerc. 1999;31(5):708716.

28. Markolf KL, Burchfield DM, Shapiro MM, Shepard MF, Finerman GA, Slauterbeck JL. Combined knee loading states that generate high anterior cruciate ligament forces. J Orthop Res. 1995;13:930-935.

29. Arms SW, Pope MH, Johnson RJ, Fischer RA, Arvidsson I, Eriksson E. The biomechanics of anterior cruciate ligament rehabilitation and reconstruction. Am J Sports Med. 1984;12:8-18.

30. Berns GS, Hull ML, Patterson HA. Strain in the anteromedial bundle of the anterior cruciate ligament under combination loading. J Orthop Res. 1992;10:167-176.

31. Kanamori A, Zeminski J, Rudy TW, Li G, Fu FH, Woo SL. The effect of axial tibial torque on the function of the anterior cruciate ligament: a biomechanical study of a simulated pivot shift test. Arthroscopy. 2002;18(4):394-398.

32. Fung DT, Zhang LQ. Modeling of ACL impingement against the intercondylar notch. Clin Biomech (Bristol, Avon). 2003;18(10):933-941.

33. Shimokochi Y, Shultz SJ. Mechanisms of noncontact anterior cruciate ligament injury. J Athl Train. 2008;43(4):396-408.

34. Kernozek TW, Torry MR. Van Hoof H, Cowley H, Tanner S. Gender differences in frontal and sagittal plane biomechanics during drop landings. Med Sci Sports Exerc. 2005;37(6):1003-1012, discussion 1013. 
35. Kernozek TW, Torry MR, Iwasaki M. Gender differences in lower extremity landing mechanics caused by neuromuscular fatigue. Am J Sports Med. 2008;36(3):554-565.

36. Mclean SG, Lipfert SW, Van Den Bogert AJ. Effect of gender and defensive opponent on the biomechanics of sidestep cutting. Med Sci Sports Exerc. 2004;36(6):1008-1016.

37. Pappas E, Hagins M, Sheikhzadeh A, Nordin M, Rose D. Biomechanical differences between unilateral and bilateral landings from a jump: gender differences. Clin J Sport Med. 2007;17(4):263-268.

38. Dempsey AR, Lloyd DG, Elliott BC, Steele JR, Munro BJ, Russo KA. The effect of technique change on knee loads during sidestep cutting. Med Sci Sports Exerc. 2007;39(10):1765-1773.

39. Fung DT, Hendrix RW, Koh JL, Zhang LQ. ACL impingement prediction based on MRI scans of individual knees. Clin Orthop Relat Res. 2007;460:210-218.

40. Simpson KJ, Jiang P. Foot landing position during gait influences ground reaction forces. Clin Biomech (Bristol, Avon). 1999;14(6):396-402.. 